\title{
Analisis Kelayakan Industri Rumah Tangga Keripik Singkong di Desa Kasarangan Kecamatan Labuan Amas Utara
}

\section{(Cassava Chips Household Industry Feasibility Analysis in Kasarangan Village Labuan Amas Utara District)}

\author{
Rum Van Royensyah ${ }^{1)}$ \& Sundariah ${ }^{2)}$ \\ Program Studi Agribisnis, Sekolah Tinggi Ilmu Pertanian Amuntai \\ ${ }^{1)}$ vanroyensyah61@ gmail.com \\ ${ }^{2)}$ sndr@yahoo.com
}

\begin{abstract}
ABSTRAK
Pengolahan singkong secara terpadu pada industri keripik singkong skala rumah tangga merupakan salah satu upaya mengoptimalkan setiap tahapan proses pengolahan singkong dan pemanfaatan hasil samping yang timbul dari industri tersebut untuk meningkatkan nilai tambah singkong. Singkong merupakan salah satu komoditi yang banyak dijumpai di daerah perdesaan seperti di Desa Kasarangan, penelitian ini bertujuan mengetahui besarnya (i) biaya produksi (ii) penerimaan (iii) keuntungan (benefit) dan (iv) kelayakan usaha dari usaha rumah tangga keripik singkong di Desa Kasarangan Kecamatan Labuan Amas Utara Kabupaten Hulu Sungai Tengah. Hasil penelitian ini menunjukan bahwa Usaha industri rumah tangga keripik singkong yang diusahakan oleh pengusaha/responden pada penelitian ini, rata-rata biaya totalnya mencapai Rp. 22.820.286,00. Ratarata biaya tetap mencapai $R p$. 2.228.649,00/ bulan dan rata-rata biaya variabel mencapai $R p$. 20.591.636,00/bulan. Adapun penerimaan rata-rata adalah $R p$. 54.000.000,00/bulan, dengan keuntungan rata-rata mencapai $R p$ 31.179.714,00/bulan. Dengan nilai rata-rata $R C R$ pada usaha tersebut mencapai 2,37 yaitu layak untuk diusahakan.
\end{abstract}

Kata Kunci: Industri, keripik, singkong, kelayakan, usaha.

\section{ABSTRACT}

Integrated processing of cassava in the household scale cassava chips industry is an effort to optimize each stage of cassava processing and the utilization of by-products arising from the industry to increase the added value of cassava. Cassava is one of the commodities that are often found in rural areas such as in Kasarangan Village, this study aims to determine the size (i) of production costs (ii) revenue (iii) benefits and (iv) business feasibility of cassava chips household business in Kasarangan Village, Labuan Amas District, North, Hulu Sungai Tengah Regency. The results of this study indicate that the business of home industries of cassava chips that were cultivated by entrepreneurs / respondents in this study, the average total cost reached Rp. 22,820,286.00. Average fixed costs reach Rp. 2,228,649.00 / month and the average variable cost reaches $R p .20,591,636.00 /$ month. The average revenue is Rp. 54,000,000.00 / month, with an average profit reaching Rp. 31,179,714.00/month. Based on the data presented, the cassava chips household industry in Kasarangan Village, Labuan Amas District, Hulu Sungai Tengah Regency. With the average RCR value of the business reaching 2.37, it is worth trying.

Keywords : Industry, chips, cassava, feasibility, business.

\section{PENDAHULUAN}

Usaha penganekaragaman pangan sangat penting dalam rangka mengatasi ketergantungan pada salah satu bahan pangan pokok. Misalnya dengan mengolah serealia dan umbi-umbian menjadi berbagai bentuk awetan yang mempunyai rasa khas dan tahan lama disimpan. Bentuk olahan tersebut berupa tepung, gaplek, tapai, keripik dan lainnya. Hal ini sesuai dengan program pemerintah khususnya dalam 
mengatasi masalah kebutuhan bahan pangan, terutama non beras (Sudaryanto, 1989).

Penganekaragaman produk olahan khususnya ubi kayu (singkong) dapat dilakukan baik pada bahan pangan segar maupun setengah jadi (produk antara) yang selanjutnya dapat langsung dipasarkan atau diolah menjadi produk makanan siap saji. Singkong diolah menjadi bahan baku untuk industry makanan misalnya pembuatan tepung tapioka, cake ubi kayu, ubi keju, kue ubi sayur (sawut), puding, singkong goreng dan masih banyak lagi fungsi dari ubi kayu dengan nilai ekonomis yang tinggi. Selain direbus atau digoreng, singkong dapat diolah menjadi keripik dengan beraneka rasa, seperti keripik singkong balado, keripik singkong pedas, keripik singkong aneka rasa dan sebagainya. Upaya penganekaragaman produk dimaksudkan untuk mengatasi melimpahnya produksi pada saat panen raya yang sering kali merugikan petani akibat merosotnya harga karena ubi kayu segar tidak tahan lama disimpan (Hastuti, 2006).

Singkong merupakan salah satu tanaman yang memiliki daya adaptasi yang tinggi terhadap berbagai kondisi tanah dan tidak memerlukan perawatan yang khusus. Singkong merupakan salah satu komoditi yang banyak dijumpai di daerah perdesaan seperti di Desa Kasarangan Kecamatan Labuan Amas Utara Kabupaten Hulu Sungai Tengah Provinsi Kalimantan Selatan, yakni lokasi tempat berlangsungnya penelitian ini. Harga per $\mathrm{kg}$ singkong relatif rendah berkisar antara $\mathrm{Rp}$ 750,- hingga Rp. 1.100,- per kg. Upaya pengolahan lanjut singkong diperlukan untuk menunjang program diversifikasi pangan dan berdampak pada peningkatan nilai tambah komoditas sehingga derajat komoditas serta pendapatan dan kesejahteraan masyarakat perdesaan pun ikut terangkat. Pengolahan singkong secara terpadu pada industri keripik singkong skala rumah tangga merupakan salah satu upaya mengoptimalkan setiap tahapan proses pengolahan singkong dan pemanfaatan hasil samping yang timbul dari industri tersebut untuk meningkatkan nilai tambah singkong.

Berdasarkan survei awal diketahui bahwa pembuatan keripik singkong di lokasi penelitian belum optimal dalam pemanfaatan setiap tahapan proses sehingga hasil yang dicapai tidak optimal, keripik singkong yang dihasilkan warnanya kurang memuaskan, keripik mudah menurun kerenyahannya dan hasil samping yang berupa kulit singkong hanya ditumpuk dalam bentuk onggokan yang semakin lama semakin menumpuk. Dengan introduksi teknologi yang disesuaikan dengan kondisi perdesaan yang serba terbatas modal dan sumberdaya manusianya diharapkan ada peningkatan tambahan pendapatan dari pengolahan singkong secara terpadu yang memperhatikan pengoptimalan setiap tahapan proses dan pemanfaatan hasil samping sehingga dapat menambah pendapatan keluarga tani.

Kabupaten Hulu Sungai Tengah merupakan daerah yang banyak memiliki industri, terutama industri kecil-menengah atau industri rumah tangga, baik industri pangan, industri sandang, industri kerajinan maupun industri jasa. Pengembangan usaha industri kecil-menengah yang menyerap ribuan tenaga kerja tersebut, Pemerintah Kabupaten Hulu Sungai Tengah telah memberikan bimbingan dan pembinaan. Bimbingan dan pembinaan tersebut dimaksudkan agar produk yang dihasilkan dari pengusaha atau pengrajin di daerah ini kualitasnya meningjkat, serta usahanya bisa meningkat ke arah skala usaha yang lebih besar (Dinas Perindustrian, Pertambangan dan Energi Kabupaten Hulu Sungai Tengah, 2012).

Desa Kasarangan Kabupaten Labuan Amas Utara, adalah merupakan sentra industri pangan dari bahan ubi kayu atau singkong, diolah menjadi keripik singkong. Selain itu juga membuat keripik pisang dan marning jagung. Jumlah pengusaha keripik singkong yang ada di Desa Kasarangan Kecamatan Labuan Amas Utara, disajikan pada tabel di bawah ini.

Tabel 1. Industri Rumah Tangga Keripik Singkong di Desa Kasarangan Kecamatan Labuan 
Amas Utara Tahun 2012.

\begin{tabular}{clcc}
\hline No & Nama Pemilik & $\begin{array}{c}\text { Kapasitas Produksi } \\
(\mathrm{kg} / \text { bulan) }\end{array}$ & $\begin{array}{c}\text { Jumlah Tenaga Kerja } \\
\text { (orang) }\end{array}$ \\
\hline 1 & Mila & 2.000 & 3 \\
2 & Yogi & 2.000 & 3 \\
3 & Bahrani & 2.200 & 4 \\
4 & Khairun & 2.000 & 3 \\
5 & Isna & 2.100 & 3 \\
6 & Salasiah & 2.400 & 4 \\
7 & Rahimah & 2.100 & 4 \\
8 & Zainun & 2.000 & 4 \\
9 & H. Arjuna & 2.300 & 4 \\
10 & M. Ahim & 2.500 & 4 \\
11 & Kamal & 2.160 & 4 \\
\hline \multicolumn{2}{c}{ Total } & 21.160 & 46 \\
\hline
\end{tabular}

Sumber : Dinas Perindustrian, Pertambangan dan Energi Kabupaten Hulu Sungai Tengah, 2012.

Penelitian ini bertujuan mengetahui besarnya (i) biaya produksi (ii) penerimaan (iii) keuntungan (benefit) dan (iv) kelayakan usaha dari usaha rumah tangga keripik singkong di Desa Kasarangan Kecamatan Labuan Amas Utara Kabupaten Hulu Sungai Tengah

\section{METODE PENELITIAN}

Penelitian ini dilaksanakan di Desa Kasarangan Kecamatan Labuan Amas Utara Kabupeten Hulu Sungai Tengah Provinsi Kalimantan Selatan. Kegiatan penelitian dilaksanakan mulai bulan Maret 2013 sampai dengan Juni 2013.

Data yang dikumpulkan berupa data primer dan data sekunder. Data primer diperoleh dari hasil wawancara langsung ke lokasi perusahaan serta wawancara dengan pimpinan dan karyawan perusahaan keripik singkong desa Kasarangan Kecamatan Labuan Amas Utara. Data sekunder untuk mendukung data primer diperoleh dari dinas/instansi terkait serta studi kepustakaan.

Penarikan data dalam penelitian ini dilakukan secara dengan metode sensus. Karena di desa Kasarangan Kecamatan Labuan Amas Utara hanya ada 11 pengusaha keripik singkong, maka semua pengusaha industri keripik singkong skala rumah tangga tersebut dijadikan sampel untuk penarikan sampel.

Data yang diambil dikumpulkan kemudian diolah dan dianalisis. Analisis meliputi biaya, penerimaan, dan keuntungan pengusaha industri rumah tangga keripik singkong.

Untuk mengetahui tujuan pertama yaitu besarnya biaya produksi, penerimaan dan keuntungan digunakan perhitungan:

Besarnya biaya total yang dikeluarkan pengusaha industri rumah tangga keripik singkong secara matematis dinyatakan dengan rumus sebagai berikut:

$$
\mathbf{T C}=\mathbf{F C}+\mathbf{V C}
$$

Dimana:

$$
\begin{aligned}
\mathrm{TC}= & \text { Biaya total (total coast }), \\
& (\mathrm{Rp} / \mathrm{bulan}) \\
\mathrm{FC}= & \text { Biaya tetap }(\text { fixed coast }), \\
& (\mathrm{Rp} / \mathrm{bulan}) \\
\mathrm{VC}= & \text { Biaya variabel (variable } \\
& \text { coast }),(\mathrm{Rp} / \mathrm{bl})
\end{aligned}
$$

Besarnya penerimaan dari usaha industri rumah tangga keripik singkong selama satu bulan, secara matematis dapat ditulis sebagai berikut:

$$
\text { TR }=\mathbf{Y}-\mathbf{P y}
$$

Dimana:

$$
\begin{aligned}
\mathrm{TR}= & \text { Penerimaan total }(\text { total } \\
& \text { revenue }), \mathrm{Rp} / \mathrm{bulan}) \\
\mathrm{Y}= & \text { Produksi per bulan } \\
\mathrm{Py} \quad= & \text { Harga produksi (price) }
\end{aligned}
$$


Untuk mengetahui keuntungan adalah penerimaan dikurangi dengan biaya total, secara matematis dapat dirumuskan sebagai berikut (Boediono, (1980) dalam Soekartawi, 1995)

Dimana:

$$
\text { Л } \quad \text { TR-TC }
$$

$$
\begin{aligned}
\pi & =\text { Keuntungan } \\
\mathrm{TR} & =\text { Total Revenue } \\
& \text { (Penerimaan total) } \\
\mathrm{TC} & =\text { Total Cost (Biaya Total) }
\end{aligned}
$$

Untuk mengetahui kelayakan usaha, dapat dipergunakan hubungan dari nilai Revenue Cost Ratio (RCR), yaitu perbandingan antara penerimaan total suatu usahatani dengan biaya total yang dikeluarkan, dengan rumus sebagai berikut:

$$
\mathrm{RCR}=\frac{T R}{T C}
$$

Dimana:

$$
\begin{aligned}
& \mathrm{RCR}=\text { Revenue Cost Ratio } \\
& \text { (Kelayakan) } \\
& \mathrm{TR}=\text { Total Revenue } \\
& \text { (Penerimaan Total) } \\
& \mathrm{TC}=\text { Total Cost (Biaya Total) }
\end{aligned}
$$

Kriteria:
1. Apabila RCR > 1, maka usahatani yang diselenggarakan layak untuk diusahakan.

2. Apabila RCR $<1$, maka usahatani tersebut tidak layak untuk diusahakan.

3. Apabila $\mathrm{RCR}=1$, maka usahatani tersebut tidak untung dan tidak rugi.

\section{HASIL DAN PEMBAHASAN}

\section{Analisis Biaya, Penerimaan dan Keuntungan}

\section{Biaya Tetap}

Pembiayaan usaha industri rumah tangga keripik singkong di tempat penelitian ini terdiri dari biaya tetap dan biaya variabel. Biaya tetap adalah biaya yang harus dikeluarkan, akan tetapi besar kecilnya biaya tidak dipengaruhi oleh besarnya produksi yang dicapai. Dalam usaha industri rumah tangga keripik singkong, komponen biaya tetap terdiri dari biaya penyusutan alat dan perlengkapan, biaya tenaga kerja dalam keluarga (TKDK), dan biaya bunga modal

Tabel 2. Rata-rata Besarnya Biaya Penyusutan Alat dan Perlengkapan yang Digunakan untuk Kegiatan Usaha Industri Rumah Tangga Keripik Singkong di Desa Kasarangan Kecamatan Labuan Amas Utara.

\begin{tabular}{clcc}
\hline No. & Jenis Alat dan Perlengkapan & $\begin{array}{c}\text { Besarnya Biaya } \\
\text { Penyusutan/periode (Rp.) }\end{array}$ & Persentase (\%) \\
\hline 1. & Pisau besar & 59,97 & 2,41 \\
2. & Wajan & 416,67 & 16,78 \\
3. & Susuk & 55,56 & 2,24 \\
4. & Serok & 20,83 & 0,84 \\
5. & Tungku & 347,22 & 13,98 \\
6. & Alat Perajang & 208,00 & 8,38 \\
7. & Ember & 52,00 & 2,10 \\
8. & Baskom packing $\quad$ plastik & 20,83 & 0,84 \\
9. & Alat penghalus bumbu & 868,06 & 34,95 \\
10 & Pengepres pack & 17,48 \\
& (Impulse Sealer) & 434,03 & 100 \\
\hline
\end{tabular}

Sumber: Data Primer Diolah 
Tabel 3. Rata-rata Besarnya Biaya Tenaga Kerja Dalam Keluarga (TKDK) yang Digunakan untuk Kegiatan Industri Rumah Tangga Keripik Singkong di Desa Kasarangan Kecamatan Labuan Amas Utara.

\begin{tabular}{|c|c|c|c|c|c|}
\hline \multirow[b]{2}{*}{ No. } & \multirow[b]{2}{*}{ Jenis Kegiatan } & \multicolumn{2}{|c|}{ Besarnya Biaya (Rp.) } & \multirow[b]{2}{*}{ Jumlah (Rp) } & \multirow[b]{2}{*}{$\%$} \\
\hline & & $\begin{array}{c}\text { TKDK } \\
\text { Pria }\end{array}$ & $\begin{array}{l}\text { TKDK } \\
\text { Wanita }\end{array}$ & & \\
\hline 1 & Pengupasan Kulit & 32.400 & 75.600 & 108.000 & 4,87 \\
\hline 2 & Pencucian & 0 & 32.400 & 54.000 & 2,43 \\
\hline 3 & Perajangan & 21.600 & 0 & 216.000 & 9,74 \\
\hline 4 & Perendaman dlm air kapur & 216.000 & 4.320 & 4.320 & 0,19 \\
\hline 5 & Penggorengan & 0 & 216.000 & 216.000 & 9,74 \\
\hline 6 & Pembuatan bumbu & 0 & 1.080 .000 & 1.080 .000 & 48,68 \\
\hline 7 & Pencampuran dengan bumbu & 0 & 216.000 & 216.000 & 9,74 \\
\hline 8 & Pengepakan & 81.000 & 27.000 & 108.000 & 4,87 \\
\hline 9 & Pemasaran & 108.000 & 108.000 & 216.000 & 9,74 \\
\hline & Jumlah: & 459.000 & 1.759 .320 & 2.352 .123 & 100 \\
\hline
\end{tabular}

Sumber: Data Primer Diolah

Tabel 4. Rata-Rata Biaya Tetap yang Dikeluarkan Responden yang Mengusahakan Industri Rumah Tangga Keripik Singkong di Desa Kasarangan Kecamatan Labuan Amas Utara.

\begin{tabular}{clrc}
\hline No. & \multicolumn{1}{c}{ Biaya Tetap } & Jumlah Biaya (Rp.) & $(\%)$ \\
\hline 1. & Biaya penyusutan alat & $2.483,59$ & 0,11 \\
2. & Biaya TKDK & $2.218 .320,00$ & 99,54 \\
3. & Biaya Bunga Modal & $7.825,00$ & 0,35 \\
\hline & Jumlah : & $2.228 .628,59$ & 100,00 \\
\hline
\end{tabular}

Sumber: Data Primer Diolah

\section{Biaya Variabel}

Biaya variabel adalah biaya yang harus dikeluarkan pada suatu usaha yang besar kecilnya tergantung pada jumlah produksi yang dicapai. Biaya Variabel juga mempunyai hubungan yang erat dengan besar kecilnya atau tinggi rendahnya output yang dihasilkan. Komponen biaya variabel pada usaha industri rumah tangga keripik singkong tani kacang tanah terdiri dari biaya bahan, biaya peralatan dan perlengkapan, serta biaya tenaga kerja luar keluarga (TKLK). 
Tabel 5. Rata-rata biaya variabel yang dikeluarkan responden dari usaha industri rumah tangga keripik singkong di Desa Kasarangan Kecamatan Labuan Amas Utara dalam satu bulan.

\begin{tabular}{crrr}
\hline No. & \multicolumn{1}{c}{ Biaya Variabel } & Jumlah Biaya (Rp.) & Persentase (\%) \\
\hline 1. & Biaya bahan: & $19.026 .636,00$ & $92,40 \%$ \\
& a. Singkong & $4.104 .000,00$ & \\
b. Minyak Goreng & $619.982,00$ & \\
c. Bawang Putih & $1.800 .000,00$ & \\
d. Bawang Merah & $3.888,000,00$ & \\
e. Cabai Merah & $3.601,818,00$ & \\
f. Ketumbar & $2.430 .000,00$ & \\
g. Gula Pasir & $2.376 .000,00$ & \\
h. Garam Dapur & $43.200,00$ & \\
i. Kapur Sirih & $36.364,00$ & \\
j. Asam Kamal & $127.273,00$ & \\
Biaya Peralatan \& Perlangkapan & $1.565 .000,00$ & 7,60 \\
Biaya TKLK & 0,00 & 0,00 \\
\hline Jumlah : & $20.591 .636,00$ & 100 \\
\hline
\end{tabular}

Sumber: Data Primer Diolah

\section{Penerimaan}

Penerimaan usaha industri rumah tangga keripik singkong dalam penelitian ini dihitung selama satu bulan, dalam satu bulannya hanya dilaksanakan kegiatan selama 20 hari. Besarnya penerimaan adalah besarnya produksi keripik singkong dikalikan dengan harga yang berlaku di tingkat pengusaha. Rata-rata jumlah produksi keripik singkong dari responden di desa penelitian ini adalah sebesar 2.160,00 $\mathrm{kg} / \mathrm{bulan}$.

Tabel 6. Rata-rata Penerimaan Pengusaha Industri Rumah Tangga Keripik Singkong di Desa Kasarangan Kecamatan Labuan Amas Utara selama Satu Bulan.

\begin{tabular}{cccc}
\hline No. & Jumlah Produksi $(\mathrm{kg})$ & Harga per kg (Rp.) & Jumlah Penerimaan $(\mathrm{Rp})$. \\
\hline 1. & $2.160,00$ & $25.000,00$ & $54.000 .000,00$ \\
\hline
\end{tabular}

Sumber: Data Primer Diolah

\section{Keuntungan}

Keuntungan adalah besarnya penerimaan dikurangi dengan biaya total. Keuntungan rata-rata pengusaha/responden dari Desa Kasarangan Kecamatan Labuan Amas Utara yang mengusahakan keripik singkong skala rumah tangga dapat dilihat pada Tabel 7 .

Tabel 7. Rata-rata Keuntungan yang Diperoleh Responden yang mengusahakan Keripik Singkong dari Desa Kasarangan Kecamatan Labuan Amas Utara dalam satu Bulan.

\begin{tabular}{cccc}
\hline No. & Penerimaan Rata-rata (Rp.) & $\begin{array}{c}\text { Biaya Total Rata-rata } \\
\text { (Rp.) }\end{array}$ & $\begin{array}{c}\text { Keuntungan rata-rata } \\
\text { (Rp./usahatani) }\end{array}$ \\
\hline 1. & $54.000 .000,00$ & $22.820 .265,00$ & $31.179,735,00$ \\
\hline
\end{tabular}

Sumber: Data Primer Diolah 


\section{Kelayakan Usaha (Revenue Cost Ratio)}

Untuk mengetahui kelayakan usaha dari usaha industri rumah tangga keripik singkong di Desa Kasaranganh Kecamatan
Labuan Amas Utara, yaitu dengan cara membandingkan antara penerimaan total suatu usaha dengan biaya total yang dikeluarkan.

Tabel 16. Rata-rata Besarnya RCR pada usaha industri rumah tangga keripik singkong Di Desa Kasarangan Kecamatan Labuan Amas Utara.

\begin{tabular}{cccc}
\hline No. & Rata-rata Penerimaan (Rp) & $\begin{array}{c}\text { Biaya Total Rata-rata } \\
(\mathrm{Rp} .)\end{array}$ & Rata-rata RCR \\
\hline 1. & $54.000 .000,00$ & $22.820 .265,00$ & 2,37
\end{tabular}

Sumber: Data Primer Diolah

\section{KESIMPULAN}

Usaha industri rumah tangga keripik singkong di Desa Kasarangan Kecamatan Labuan Amas Utara Kabupaten Hulu Sungai Tengah, rata-rata biaya totalnya mencapai Rp. 22.820.265,00. Rata-rata biaya tetap mencapai Rp. 2.228.629,00/ bulan dan rata-rata biaya variabel mencapai Rp. 20.591.636,00/bulan. Adapun penerimaan rata-rata adalah $\mathrm{Rp}$. 54.000.000,00/bulan, dengan keuntungan rata-rata mencapai $R p 31.179 .735,00 /$ bulan. Nilai rata-rata RCR pada usaha tersebut mencapai 2,37 yaitu layak untuk diusahakan.

\section{DAFTAR PUSTAKA}

Dinas Perindustrian, Pertambangan dan Energi. 2011. Data Potensi Komoditi UnggulanDaerah Kabupaten Hulu Sungai Tengah. Kabupaten Hulu Sungai Tengah.

Dinas Perindustrian, Pertambangan dan Energi. 2011. Daftar Sentra Industri Kecil dan Menengah. Kabupaten Hulu Sungai Tengah.

Sudaryanto, 1989. Kulit Ubi sebagai Bahan Pakan ternak. Dalam Warta Litbang Pertanian.No. 3 Vol. XI Mei 1989. Departemen Pertanian.

Soekartawi, 1995. Analisis Usahatani. Universitas Indonesia. Jakarta.
Hastuti, S., Ulyata, Prisdiminggo, 2006. Peranan Industri Pengolahan Keripik Singkong Dalam Menggerakkan Perekonomian Pedesaan. Kasus di Desa Padamara, Kabupaten Lombok Timur. Balai Pengkajian Teknologi Pertanian NTB. 